\title{
Children's meta-talk in their collaborative decision making with peers
}

\author{
Bahar Köymen $^{\mathrm{a}, *}$, Michael Tomasello ${ }^{\mathrm{b}, \mathrm{c}}$ \\ ${ }^{a}$ University of Manchester, Manchester M13 9PL, UK \\ ${ }^{\mathrm{b}}$ Max Planck Institute for Evolutionary Anthropology, 04103 Leipzig, Germany \\ ${ }^{\mathrm{c}}$ Duke University, Durham, NC 27708, USA
}

\section{A R T I C L E I N F O}

\section{Article history:}

Received 4 May 2017

Revised 15 September 2017

Available online 1 November 2017

\section{Keywords:}

Reasoning

Reason-giving

Collaborative decision making

Cooperative problem-solving

Information reliability

Peer interactions

\begin{abstract}
A B S T R A C T
In collaborative decision making, children must evaluate the evidence behind their respective claims and the rationality of their respective proposals with their partners. In the main study, 5and 7-year-old peer dyads $(N=196)$ were presented with a novel animal. In the key condition, children in a dyad individually received conflicting information about what the animal needs (e.g., rocks vs. sand for food) from sources that differ in reliability (with first-hand vs. indirect evidence). Dyads in both age groups were able to reliably settle on the option with the best supporting evidence. Moreover, in making their decision, children, especially 7-year-olds, engaged in various kinds of meta-talk about the evidence and its validity. In a modified version of the key condition in Study 2, 3- and 5-year-olds $(N=120)$ interacted with a puppet who tried to convince children to change their minds by producing meta-talk. When the puppet insisted and produced meta-talk, 5year-olds, but not 3-year-olds, were more likely to change their minds if their information was unreliable. These results suggest that even preschoolers can engage in collaborative reasoning successfully, but the ability to reflect on the process by stepping back to jointly examine the evidence emerges only during the early school years.
\end{abstract}

(c) 2017 Elsevier Inc. All rights reserved.

\footnotetext{
* Corresponding author.

E-mail address: bahar.koymen@manchester.ac.uk (B. Köymen).
} 


\section{Introduction}

Reasoning-in the sense of explicating reasons for actions-is a fundamentally social skill enabling people to produce and evaluate arguments to reach joint decisions (Mercier \& Sperber, 2011; Tomasello, 2014). Sperber et al. (2010) argued that in a world of mistrust, where everyone is practicing "epistemic vigilance", individuals win others over to their point of view by providing good reasons, which will be accepted based not on trust but rather on logic and evidence. On the other hand, Tomasello (2014) stressed that reasoning is also critical in situations of trust; if the joint decision benefits both parties, then individuals want to make the best decision based on logic and evidence (regardless of who "wins" the argument), so they produce and evaluate reasons cooperatively as a means to that end.

Research on testimony suggests that young children are vigilant social learners and selectively trust certain information sources more than others. At around preschool ages, children prefer to learn new information from informants who accurately label familiar objects more than those who do not (Corriveau \& Harris, 2009; Koenig \& Harris, 2005), from informants who express their expertise/knowledge more than those who express uncertainty (Sabbagh \& Baldwin, 2001; Sobel \& Corriveau, 2010), and from informants who produce noncircular arguments more than those who produce circular arguments (Corriveau \& Kurkul, 2014; Mercier, Bernard, \& Clément, 2014).

Nevertheless, in most of these studies, children were asked to choose the more reliable informant out of the two informants rather than evaluating the reliability of a single informant in the absence of a reference point. Moreover, all of these were comprehension studies in which children did not need to justify their decisions to convince a partner. Justifying a decision about information reliability for a partner is an advanced meta-cognitive skill because speakers need to go beyond the content of the message. First, they need to refer to their information source in their justifications (where or from whom they received the information). Next, they need to express how reliable their information source is and express why they believe this piece of information is therefore reliable (Kuhn, 2001; Mahr \& Csibra, 2017). Although preschoolers produce explanations when they have disagreements with others (Dunn \& Munn, 1987; Kyratzis \& Ervin-Tripp, 1999) and when they encounter information contradicting their prior beliefs (Legare, 2012; Young, Alibali, \& Kalish, 2012), to date only much older children (around 11 or 12 years) have been observed to use meta-argumentative strategies, or metatalk, aimed at assessing the validity of arguments and/or evidence directly (e.g., "Tell us where you got that evidence"; Kuhn, Zillmer, Crowell, \& Zavala, 2013, p. 466). However, it is possible that young children have so far not been observed in the right situations, that is, not in situations of dispute but rather in situations of collaborative decision making in which both participants are motivated to get the right answer.

In Study 1, therefore, we created an interactive context in which two peers would need to jointly solve a problem to reach correct joint decisions for a reward and investigated whether/how they produced meta-talk, explanations about the information source and the information reliability, for their decisions. We introduced 5- and 7-year-old peer dyads to a novel animal, called a "selk," with three unique characteristics (e.g., eating rocks). Each child learned about the novel animal individually from an informant in a clip. In the critical condition, the unequal reliability condition, children within a dyad received conflicting information (e.g., one child was told that selks eat only rocks, and the other was told that they eat only sand) from sources that differ in reliability (one child watched a first-hand report by a selk, and the other watched a second-hand report by a girl who expressed uncertainty). In the equal reliability condition, children received conflicting information from the same source (both children watched first-hand reports or both watched second-hand reports). In the same information condition, children received the same information from different sources (one child watched a firsthand report, and the other watched a second-hand report). Later, each dyad needed to decorate the home for the novel animal and jointly decide on three items that it needs. We predicted that children would favor the items supported by the first-hand report in the unequal reliability condition and in the same information condition, whereas they would favor items randomly in the equal reliability condition. We also predicted that children would produce justifications and meta-talk more in the two conditions where children had conflicting information than in the same information condition (see Legare, 2012). We explored whether there were any age differences in children's argumentation because 
studies have shown that preschoolers robustly know whom to trust (Corriveau \& Kurkul, 2014; Mercier et al., 2014), but they do not normally talk about information reliability until adolescence (Kuhn et al., 2013).

In Study 2, we explored whether preschoolers, 3- and 5-year-olds, would be able to choose the correct item if a puppet partner provided the necessary meta-talk (e.g., asking children who their source is, asking children whether their source was sure or not) and directed their attention to the reliability of the information because the literature suggests that preschoolers are able to gauge the information reliability depending on the informants' accuracy and certainty (Corriveau \& Harris, 2009; Sabbagh \& Baldwin, 2001).

\section{Study 1}

\section{Method}

\section{Participants}

In total, 98 5-year-olds ( $M=5 ; 9$ [years;months], range $=5 ; 6-6 ; 0,48$ girls) and 98 7-year-olds $(M=$ $7 ; 6$, range $=7 ; 1-8 ; 0,48$ girls $)$ in same-age, same-sex dyads participated in the study. The dyads comprised children who knew each other based on their teachers' recommendations. There were 165 year-old dyads and 17 7-year-old dyads in the unequal reliability condition, 16 5-year-old dyads and 167 -year-old dyads in the equal reliability condition, and 17 5-year-old dyads and 167 -year-old dyads in the same information condition. The children were native speakers of German with various socioeconomic backgrounds.

\section{Materials}

In the warm-up, there was a dollhouse with three rooms: a bathroom, a kitchen, and a bedroom. There was a bin and a set of three drawers. Each drawer had two items: one that typically belonged to a room (a toilet, a fridge, or a cradle) and the other that did not (a lamp, a ladder, or a table). From each drawer, children needed to place one item in a room and the other in the bin.

In the teaching phase, each child watched one of the four clips (a slide show with four drawings) narrated by the same child. Two clips presented "strong evidence", a first-hand report. In the first slide, the novel animal (the selk) introduced itself. In the next three slides, the selk presented selks' unique characteristics: what they eat, what they drink, and where they sleep (see Appendix A for the full narration in German and its translation in English). The two clips presented the following conflicting information:

- Strong-evidence clip with Set 1: A selk stated that selks eat rocks, drink blue soda, and sleep on water.

- Strong-evidence clip with Set 2: A selk stated that selks eat sand, drink green soda, and sleep on flowers.

The other two clips presented "weak evidence", a second-hand report by a girl called Lisa who expressed uncertainty. In the first slide, Lisa introduced herself. In the next three slides, she presented what selks eat, what they drink, and where they sleep. In each slide, Lisa stated how unsure she was about her knowledge and how strange she found this to be (see Appendix B for the full narration in German and its translation in English). The two clips presented the following conflicting information:

- Weak-evidence clip with Set 1: Lisa stated that somebody told her that selks eat rocks, drink blue soda, and sleep on water.

- Weak-evidence clip with Set 2: Lisa stated that somebody told her that selks eat sand, drink green soda, and sleep on flowers.

In the experimental phase, there was a three-dimensional (3D) selk figure, a yellow cloth (selk's home), three drawers, a box, and a bin. The box had a tree to be placed in the selk's home and a piano 
in the bin (by the experimenter to demonstrate the game). Children needed to choose between rocks and sand in the top drawer, between a blue soda and a green soda in the middle drawer, and between pictures of a lake and a meadow in the bottom drawer.

\section{Procedure}

The study took place in quiet rooms of nursery schools. All sessions were videotaped. In the warmup phase, the experimenter (E1) introduced the two children to the dollhouse. She asked them to choose one item from each drawer for a room and to throw the other in the bin. E1 asked "why?" to encourage children to explain their decision for each item. If children did not answer, E1 provided a reason ("Because one needs a toilet in the bathroom"). At the end, E1 showed a photo of the correctly furnished house and said, "You did it correctly" or "You did not pick the correct item for this room, but the rest was correct," to highlight that there is a correct choice in the game.

In the teaching phase, a second experimenter (E2) asked one randomly chosen child, Child A, to go outside to play with her. With Child A outside, Child B watched a clip. Then, Child B went outside to play with E2 and Child A watched a clip. We used clips instead of live informants because children in our pilot data did not want to contradict the adult informants. In all conditions, each child in a dyad watched a different clip:

- Unequal reliability condition: Children received conflicting information from different sources. If Child A watched the strong evidence clip with Set 1, then Child B watched the weak evidence clip with Set 2.

- Equal reliability condition: Children received conflicting information from the same source. If Child A watched the strong-evidence clip with Set 1, then Child B watched the strong-evidence clip with Set 2. Eight dyads in each age group watched strong-evidence clips, and eight dyads watched weak-evidence clips.

- Same information condition: Children received the same information from different sources. If Child A watched the strong-evidence clip with Set 1, then Child B watched the weak-evidence clip with Set 1.

The presentation order of the set of items (Set 1 or Set 2) and the type of evidence (strong or weak) supporting each set were counterbalanced across dyads.

In the testing phase, E1 said, "In our zoo game, selks live here [placing a selk]. In each of these three drawers, there is one item that selks need. You place one in their home and the other in the bin. For example, the box has a tree and a piano. The selks need a tree, so I put the tree in their home, the piano in the bin. Now it is your turn: the top drawer first, the middle next, and the bottom last. If you find the right items, you will both get a surprise gift." E1 left the room until children were finished. If children placed both or none of the items from a drawer, E1 told them that they needed to choose one from each drawer and left the room again. At the end, the experimenter gave each child a sticker. Children's conversations in the testing phase were transcribed.

\section{Coding}

First, we coded which three items were chosen. Second, we coded how children reached joint decisions. For each of the three items, each dyad received one of the following codes:

- No disagreement if children reached a joint decision without disagreeing with one another, nonverbally agreed on an item, or simply asked each other questions (e.g., "This one or this one?", "Are you sure?").

- Give up if children disagreed with one another and one of them just gave up without explaining why (e.g., "No rocks!", “No, the blue one!").

- Turn taking if children disagreed with one another and resolved their disagreement by playing games such as rock-paper-scissors.

- Justification if children disagreed with one another, they explained to each other their reasons for their disagreement, and one of them gave in. The justifications could be in the form of explanations of what they saw in their clips (e.g., "But in my film, it was rocks"), how reliable the information 
source was (e.g., "She said she was not sure"), and/or ad hoc explanations to justify a choice of items (e.g., "Sand is made of rocks").

Next, we coded children's meta-talk explaining their choice of items with the following categories from the most advanced to the least advanced:

- Advanced meta-talk (score 3) if they talked about the reliability of the information for any item and/or identified the different speakers in each clip (a selk vs. a girl called Lisa), so they realized that they received information from different sources (e.g., "He said, 'Someone told me ....' What one said may not be correct"; "But I heard it from a selk/girl"; "She was not sure whether it drinks blue soda"; "Okay fine, I am not so sure about that").

- Questions (score 2) if they did not produce advanced meta-talk but tried to elicit meta-talk from one another by asking their partner to reevaluate his or her proposal or to justify the proposal (e.g., "Where did you hear that?", "Are you sure?", "Why?").

- Quotes (score 1) if their meta-talk was limited to mentioning their information source (e.g., the speaker, the video) and focusing only on the content of the message (e.g., "He said he eats rocks there").

- No meta-talk (score 0) if they produced proposals without any justifications (e.g., "No blue soda!").

If a dyad used more than one of the above strategies, they received the score of the more advanced strategy.

A second coder, who was blind to the predictions and conditions, recoded $25 \%$ of the transcripts (24 dyads: 4 dyads from each age and condition) for the kinds of joint decisions and meta-talk, and the agreements were $\kappa=.81$ and $\kappa=.82$, respectively.

\section{Results}

First, we analyzed whether there were differences in children's choice of the items across age groups and conditions by comparing the mean number of "correct items" supported by strong evidence with chance. In the equal reliability condition, because there was no correct choice, we compared the mean number of Set 1 items with chance. In the unequal reliability condition, both age groups chose the correct items significantly above chance [5-year-olds: $t(15)=5.48, p<.001, d=$ 1.37; 7-year-olds: $t(16)=2.82, p=.01, d=0.68$ ] (see Fig. 1 ). In the equal reliability condition, both age groups' preference for Set 1 was at chance [5-year-olds: $t(15)=-1.36, p=.19, d=0.34$; 7-yearolds: $t(15)=1.07, p=.29, d=0.27]$. In the same information condition, both age groups chose the correct items significantly above chance [5-year-olds: $t(16)=9.27, p<.001, d=2.25$; all 7-year-olds chose the correct items].

In the second analysis, we analyzed whether children's likelihood of expressing and justifying their disagreements changed across conditions and age groups. We used a generalized linear mixed model (GLMM) with binomial error distribution. The unit of analysis was the decision made for each item. The response variable was a binary measure of whether the children justified their disagreement or not. The full model included the predictors age group (5-year-olds or 7-year-olds) and condition (unequal reliability, equal reliability, or same information) and their interaction, the order of items (1-3), and the random factor of dyad (because we had repeated observations from each dyad). The null model included the order of items and the random factor of dyad. The full model improved the fit as compared with the null model, $\chi^{2}=60.32, d f=5, p<.001$. To test the significance of the interaction term between age group and condition, we compared the full model with a reduced model without this interaction term, and the full model did not improve the fit, suggesting that the interaction was not significant, $\chi^{2}=1.35, d f=2, p=.51$. Therefore, we dropped this interaction term to get interpretable tests of the main effects. The reduced model revealed two significant main effects. The main effect of condition suggested that children in the same information condition were less likely to express or justify their disagreements than children in other two conditions, $\chi^{2}=48.53, d f=2$, $p<.001(z s<-4.66$, $p s<.001)$ (see Fig. 2A). The unequal and equal reliability conditions did not differ 


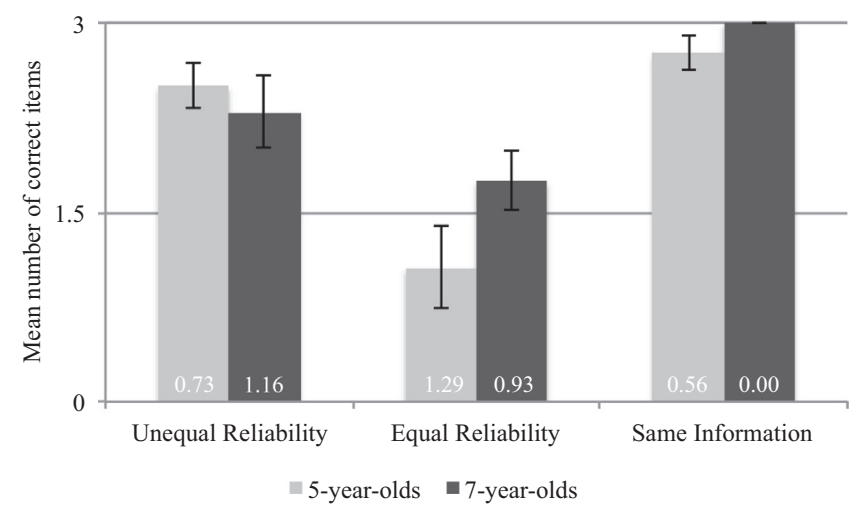

Fig. 1. Mean number of correct items chosen by each dyad across age groups and conditions compared with chance. Because there are no correct items in the equal reliability condition, the $y$ axis plots the mean number of Set 1 items for this condition. Error bars indicate standard errors, and numeric values indicate standard deviations.

from one another $(z=0.43, p=.67)$. The main effect of age group suggested that 7 -year-olds were more likely to express and justify their disagreements than 5 -year-olds, $\chi^{2}=13.23, d f=1, p<.001$. There was no significant order effect, $\chi^{2}=0.15, d f=1, p=.69$. We also ran the same GLMM for the equal reliability condition to investigate whether the likelihood of expressing and justifying their disagreements among the dyads who watched strong-evidence clips differed from those who watched weak-evidence clips. The full model included the predictors age group (5-year-olds or 7-year-olds) and type of evidence (weak or strong) and their interaction, the order of items (1-3), and the random factor of dyad. The null model included the order of items and the random factor of dyad. The full model improved the fit as compared with the null model, $\chi^{2}=13.95, d f=3, p=.003$. We tested the significance of the interaction term between the age group and the evidence type as in the previous analysis, and it was not significant, $\chi^{2}=1.55, d f=1, p=.21$, so we dropped this interaction term from the model. The reduced model revealed two significant main effects. The main effect of evidence type suggested that dyads who saw weak-evidence clips were less likely to express or justify their disagreements than those dyads who saw strong-evidence clips, $\chi^{2}=7.61, d f=1, p=.006$ (see Fig. 2B). The main effect of age group suggested that 7-year-olds were more likely to express and justify their disagreements than 5-year-olds, $\chi^{2}=5.85, d f=1, p=.02$. There was no significant order effect, $\chi^{2}=0.35$, $d f=1, p=.55$.

Finally, we looked at children's use of meta-talk. As Table 1 suggests, there were 45 -year-old dyads and 10 7-year-old dyads who produced advanced meta-talk. All 4 of the 5-year-old dyads referred to the certainty in their meta-talk. With 2 of these dyads, the child who saw the weak-evidence clip produced meta-talk (referring to uncertainty). With the other 2 dyads, the child who saw the strongevidence clip produced meta-talk (referring to certainty). Within the 7-year-old dyads, 4 dyads referred to certainty, 3 dyads referred to knowledge access, and 3 dyads referred to both.

We investigated whether dyads' production of meta-talk differed across age groups and the three conditions using the ordinal regression model because our response variable was children's meta-talk score, which was in the ordinal scale. The full model included the predictors age group (5-year-olds or 7-year-olds) and condition (unequal reliability, equal reliability, or same information) and their interaction. The null model did not include any of these factors. The full model improved the fit as compared with the null model, $\chi^{2}=41.56, d f=5, p<.001$. To test the significance of the interaction term between age group and condition, we compared the full model with a reduced model without this interaction term, and the full model did not improve the fit, suggesting that the interaction was not significant, $\chi^{2}=0.34, d f=2, p=.85$. Therefore, we dropped this interaction term to get interpretable tests of the main effects. The reduced model revealed two significant main effects. The main effect of condition suggested that children in the same information condition were less likely to 

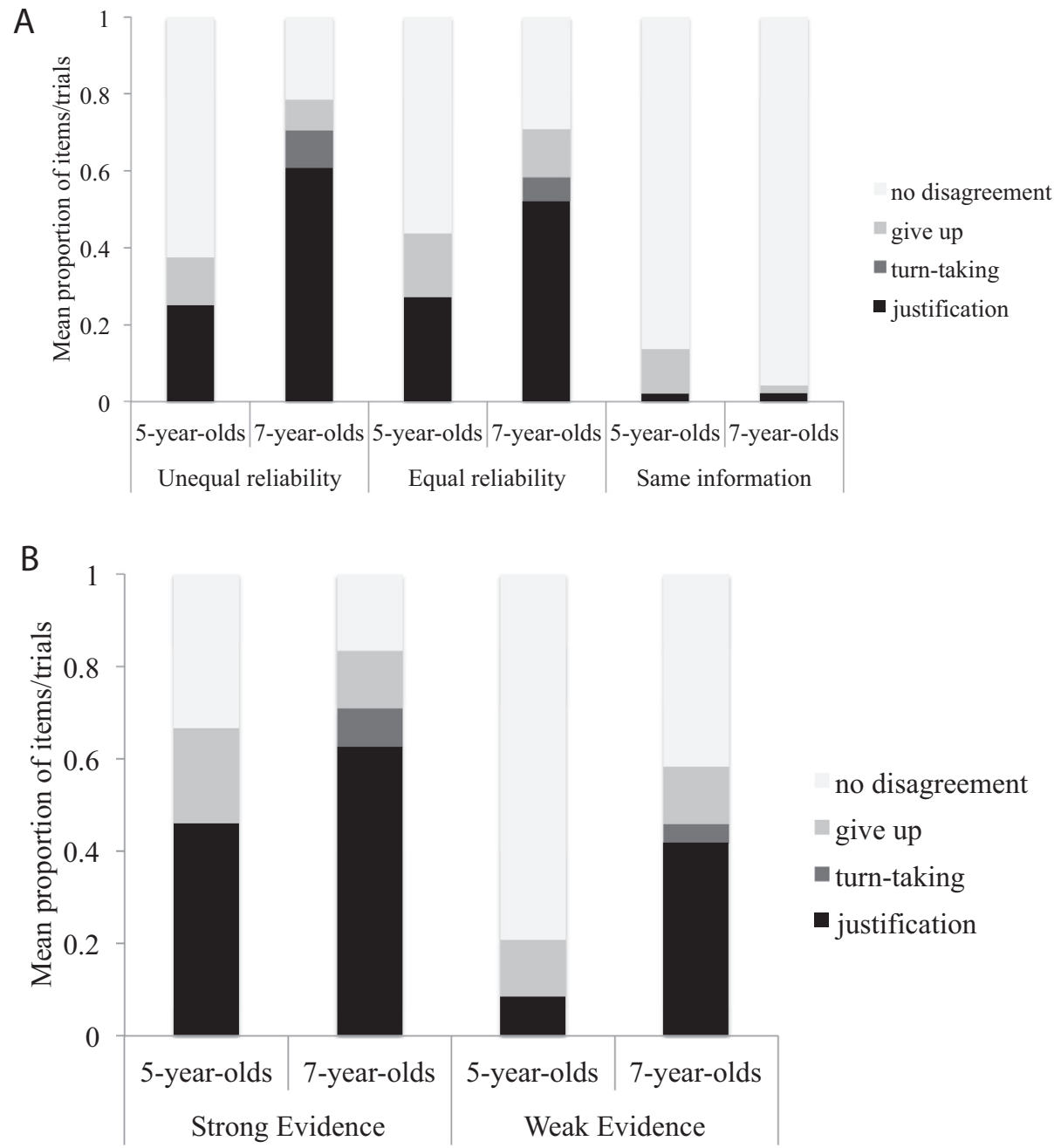

Fig. 2. (A) Mean proportion of trials with different kinds of joint decisions across the conditions and age groups. (B) Mean proportion of trials with different kinds of joint decisions in the equal reliability condition.

produce meta-talk than children in the other two conditions, $\chi^{2}=28.71, d f=2, p<.001(z s<-3.88$, ps <.001) (see Table 1 and Fig. 3). The unequal and equal reliability conditions did not differ $(z=1.04, p=.29)$. The main effect of age group suggested that 7 -year-olds were more likely to produce meta-talk than 5-year-olds, $\chi^{2}=14.01, d f=1, p<.001$.

The following excerpt shows a conversation about the food item between two 7-year-olds in the unequal reliability condition. Andi saw the strong-evidence clip with rocks (Set 1), and Sam saw the weak-evidence clip with sand (Set 2). They first disagreed with one another (lines 7 and 8) and discovered that they watched different videos (lines 11-14), after Sam asked Andi how he knows that the bowl of rocks is the correct decision (line 11). Then, they both described what they saw in their videos. In lines 14 and 16, Andi justified his proposal by saying that they have a selk (the 3D selk figure) and he saw the selk itself, who said that "selks eat rocks." In line 11, Sam agreed to take the bowl of rocks. Eventually, they chose the correct item. 
Table 1

Numbers (and proportions) of dyads with meta-talk strategies.

\begin{tabular}{llllll}
\hline & Advanced meta-talk & Questions & Quotes & None & Total \\
\hline Unequal reliability & & & & & \\
$\quad$ 5-year-olds & $2(.13)$ & $2(.13)$ & $6(.38)$ & $6(.38)$ & $16(1.00)$ \\
7-year-olds & $6(.35)$ & $3(.18)$ & $7(.41)$ & $1(.06)$ & $17(1.00)$ \\
Equal reliability & & & & & \\
$\quad$ 5-year-olds & $2(.13)$ & $2(.13)$ & $3(.19)$ & $9(.56)$ & $16(1.00)$ \\
7-year-olds & $3(.19)$ & $5(.31)$ & $6(.38)$ & $2(.13)$ & $16(1.00)$ \\
Same information & & & & & $17(1.00)$ \\
5-year-olds & $0(.00)$ & $0(.00)$ & $1(.06)$ & $16(.94)$ & $16(1.00)$ \\
7-year-olds & $1(.06)$ & $2(.13)$ & $2(.13)$ & $11(.69)$ & \\
\hline
\end{tabular}

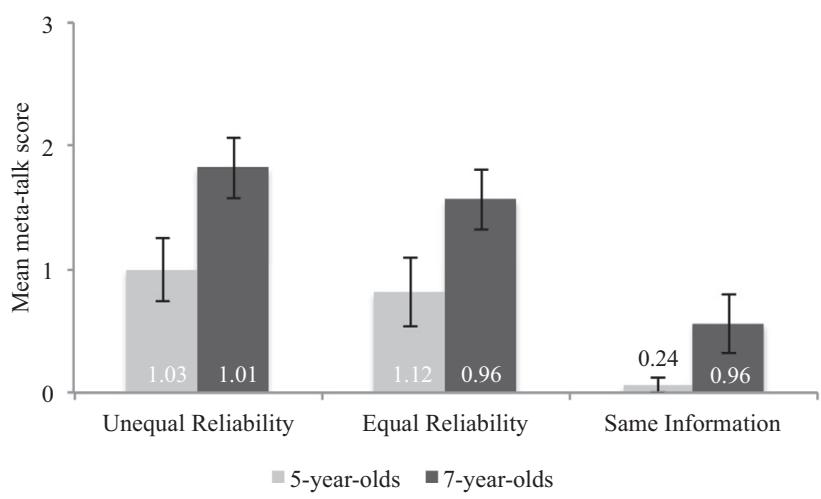

Fig. 3. Mean meta-talk scores. Error bars indicate standard errors, and numeric values indicate standard deviations.

\section{Example 1}

[First 6 lines skipped in which they disagreed about whether it is sand or rocks]

\section{Sam: Nur Sand.}

Only sand.

8 Andi: Nur Steine.

Only rocks.

9 Sam: Hmm, also was soll nun richtig sein?

$\mathrm{Hmm}$, but what is the right thing then?

10 Andi: Das ist richtig. [pointing at the rocks]

This is right. [pointing at the rocks]

11 Sam: Woher willst du das wissen?

How do you know?

12 Andi: Weil ich das Video gesehen und da stand da drauf. "Wir Selken-Wir Selken essen nur

Steine." Hast du das Video auch gesehen auf dem LapTop?

Because I saw that in the video and that's what it said, "We selks-We selks eat only rocks." Did you also see the video on the laptop?

13 Sam: Das war bestimmt ein anderes. Da war so ein Mädchen; das war nur ein Bild. Und da haben die [: sand] und da hatte die so ne Schüssel und hat gesagt-und so gesagt: "Einer hat mir gesagt, dass sie nur Sand essen." 
It was certainly a different one. There was a girl; that was only a picture. And there she had a bowl like this and said-and said like this, "Someone told me that they eat only sand."

14 Andi: Ich hab ein ganz anderes Video gehabt. Aber das war doch kein Mädchen. Das hier ist ein Selk! Kein Mädchen. [pointing at the 3D selk]

I had a very different video. But there was no girl. This here is a selk, not a girl. [pointing at the 3D selk]

15 Sam: Ja, aber bei mir war es ein Mädchen.

Yes, but with me, there was a girl.

16 Andi: Ja, und das ist ein Selk. Und bei mir war es ein Selk. Und die haben gesagt, die essen nur Steine.

Yes, and this is a selk. And with me, there was a selk, and they said they eat only rocks.

17 Sam: Dann nehmen wir deins.

Then we take yours.

The following excerpt shows a conversation about the food item between two 5 -year-olds in the unequal reliability condition. Tom saw the strong-evidence clip with sand (Set 2), and Nico saw the weak-evidence clip with rocks (Set 1 ). As can be seen, there is no disagreement about the choice between rocks and sand. Nico immediately agrees with Tom in line 2 and then says, "Hopefully that was right." Tom reassures him and justifies his proposal of sand by saying that this is what he saw in the video. Eventually, they chose the correct item.

\section{Example 2}

\begin{tabular}{|c|c|c|}
\hline 1 & Tom: & $\begin{array}{l}\text { Guck mal. Was braucht der? Sand! } \\
\text { Look, what does it need? Sand! }\end{array}$ \\
\hline 2 & Nico: & $\begin{array}{l}\text { Ja, Sand. ... Nein, in die Schublade-der [: rocks] kommt in den Karton! } \\
\text { Hoffentlich war das richtig, Sand. }\end{array}$ \\
\hline & & $\begin{array}{l}\text { Yes, sand. ... No, into the drawer-it [: rocks] goes into the bin. } \\
\text { Hopefully that was right, sand. }\end{array}$ \\
\hline 3 & Tom: & $\begin{array}{l}\text { Ja, wir haben doch gerade eben das Video gesehen. } \\
\text { Yes, we did just see the video. }\end{array}$ \\
\hline
\end{tabular}

\section{Discussion}

The results of Study 1 showed that in the critical condition, the unequal reliability condition, when children received conflicting information from different sources, both age groups endorsed the information supported by strong evidence in their joint decisions. When they received conflicting information from equally reliable sources (equal reliability condition), they chose the items randomly. These results suggest that by 5 years of age, children are able to reach the "correct" joint decisions and endorse the information that contradicted their prior knowledge when their prior knowledge was from a less reliable source.

While reaching these joint decisions, the communicative strategies differed across age groups and conditions. The two conditions in which children received conflicting information (equal reliability and unequal reliability conditions) elicited significantly more justifications for disagreements, as well as meta-talk, than the condition where children received the same information (same information condition). Moreover, 7-year-olds produced more meta-talk than 5-year-olds (see Examples 1 and 2 above). Despite this age difference in the communicative strategies, there was no age difference in their choice of items, especially in the main condition, the unequal reliability condition. Yet, how 
5-year-olds decided on the correct items in the unequal reliability condition is unclear. Thus, in Study 2a, we modified the unequal reliability condition to better understand how 5-year-olds reached correct decisions. Instead of interacting with a peer, we had individual children interact with a puppet partner because we wanted to control what the puppet partner said, especially how much the puppet disagreed and insisted and how much meta-talk the puppet produced. We investigated whether individual children would be more likely to change their minds, depending on the reliability of the information they receive and depending on the reliability of the information their partner reports. In addition, we tested younger preschoolers, 3-year-olds, to see whether they would be able to choose the items in the unequal reliability condition in a simplified procedure like this one.

Just like in the unequal reliability condition in Study 1, each child watched a clip and the puppet pretended to have watched a different clip. The child and the puppet received conflicting information. In the strong-evidence condition, children have seen a strong-evidence clip and the puppet pretended to have seen a weak-evidence clip. In the weak-evidence condition, children have seen a weakevidence clip and the puppet pretended to have seen a strong-evidence clip. In both conditions, the puppet disagreed with the child and produced the same amount of meta-talk to draw children's attention to the information reliability (e.g., "Who did you hear this from? I heard it from a girl/selk," "Was the girl/selk in your film sure? The girl/selk in my film was [not] sure"). We investigated whether 3and 5-year-olds would be able to comprehend meta-talk and favor the items supported by the strong evidence because the literature has shown that 5-year-olds, and 3-year-olds to some extent, could evaluate an informant's certainty and the argument quality (Corriveau \& Kurkul, 2014; Mercier et al., 2014; Sabbagh \& Baldwin, 2001).

\section{Study 2a}

\section{Method}

\section{Participants}

In total, 40 3-year-olds $(M=3 ; 9$, range $=3 ; 6-4 ; 0,20$ girls $)$ and 405 -year-olds $(M=5 ; 9$, range $=5$ ;5-6;1, 20 girls), who did not participate in Study 1, participated in the current study. There were 3 additional children (two 3-year-olds and one 5-year-old) who could not be included in the analyses because they either refused to give any answers or gave irrelevant answers to questions. The children were native speakers of German and had various socioeconomic backgrounds.

\section{Materials}

The materials were the same as in Study 1.

\section{Procedure}

The warm-up was the same as in Study 1 except that a puppet called "Maxi" replaced one of the children and acted like a partner of the child. While decorating the dollhouse, the puppet asked the child which item they should choose. If the child responded with the correct item (e.g., choosing toilet for the bathroom), the puppet agreed with the child. If the child responded incorrectly (e.g., choosing lamp for the bathroom), the puppet proposed to place the correct item and let the child decide eventually. Then the experimenter said, "Now I have a new game for you two. Now you [the child] will watch a film inside and Maxi will watch a film outside." Then the puppet left the room.

In the teaching phase, each child watched one of the four clips twice. Then, each child also heard E1 commenting on the clip to draw children's attention to information sources. The experimenter said, "Wow, you saw the selk itself" if the child had seen a strong-evidence clip; the experiment said, "Hmmm, Lisa was not sure at all, right?", if the child had seen a weak-evidence clip. In the weakevidence condition, children watched a weak-evidence clip (e.g., with Set 1) and the puppet pretended to have seen a strong-evidence clip (e.g., with Set 2). In the strong-evidence condition, children watched a strong-evidence clip (e.g., with Set 1) and the puppet pretended to have seen a weakevidence clip (e.g., with Set 2 ). The set of items (Set 1 or Set 2 ) supported by weak or strong evidence was counterbalanced. 
Like the testing phase in Study 1, E1 instructed the child and the puppet to jointly decide and choose one item that the selks need from each of the three drawers and left the room. Alone with the child, the puppet led the conversation and said, "Did you see the film? I saw the film too. Let's open the top drawer." After the child took out the bowl of sand and the bowl of rocks, the puppet asked, "What was the food in your film? Was it sand like this? Or was it rocks like this?" Then, the puppet said, "In my movie, the food was sand/rocks. Who said that in your film? Was it a selk like this [pointing at the animal] or someone else?" Then, the puppet reported her own source: "In my movie, it was the selk like this" or "In my movie, it was a girl called Lisa" depending on which clip the puppet was pretending to have seen. Next, the puppet said, "Was the selk/girl sure?" Finally, the puppet said, "In my film, the selk was sure" or "In my film, the girl was not sure at all." The rates of correct responses for these questions were the following:

- "What was the [food/drink/sleep] item in your clip?": The 3- and 5-year-olds responded to this question correctly $86 \%$ and $98 \%$ of the time, respectively.

- "Who said that?": The 3- and 5-year-olds responded to this question correctly $80 \%$ and $90 \%$ of the time, respectively.

- "Was she sure?": The 3- and 5-year-olds responded to this question correctly $58 \%$ and $80 \%$ of the time, respectively. If we look only at the responses in the weak-evidence condition, 3- and 5-yearolds responded correctly $30 \%$ and $60 \%$ of the time, respectively.

At the end, the puppet asked the child which item they should choose and asked the child why he or she chose that item to give the child a chance to explain his or her decision.

\section{Coding}

We first coded which items children chose. Next, we coded how children justified their choices with the following categories from most advanced to least advanced:

- Meta-talk: Reference to information reliability such as "The selk was sure" and "Lisa was not sure."

- Quotes: Reference to the content of the message without meta-talk such as "Because it is their food" and "In my film, they eat rocks."

- No/incomplete/irrelevant justifications such as "Because I like green."

A second coder recoded the justification types of $20 \%^{1}$ of the children ( 24 children in all conditions and ages), and the agreement was $\kappa=.86$.

\section{Results}

We first analyzed whether children chose the correct items supported by strong evidence and compared the number of correct items chosen by children with chance. In the strong-evidence condition where the correct items corresponded to what children had seen in their videos, both age groups were able to choose the correct items significantly above chance [3-year-olds: $t(19)=4.27, p<.001$, $d=0.95$; 5-year-olds: all children chose the correct items] (see Fig. 4). In the weak-evidence condition where the correct items did not correspond to what the children had seen in their videos, 3-year-olds were marginally below chance and chose mostly what they had seen, $t(19)=-1.85, p=.08, d=0.41$ (see Fig. 4), whereas 5-year-olds were at chance and did not show a preference between the items they had seen in the videos and the items that the puppet had suggested, $t(19)=-0.76, p=.46, d=0.17$ (see Fig. 4).

Next, we analyzed whether children's preference for the items that they had seen in the videos ("own" items) changed across conditions and age groups using analysis of variance (ANOVA). The response variable was the number of own items $(0-3)$. The between-participants factors were age

\footnotetext{
${ }^{1}$ Because the coding in Study 2a and Study $2 \mathrm{~b}$ was the same, the sample in the reliability coding also included justifications from Study $2 b$.
} 


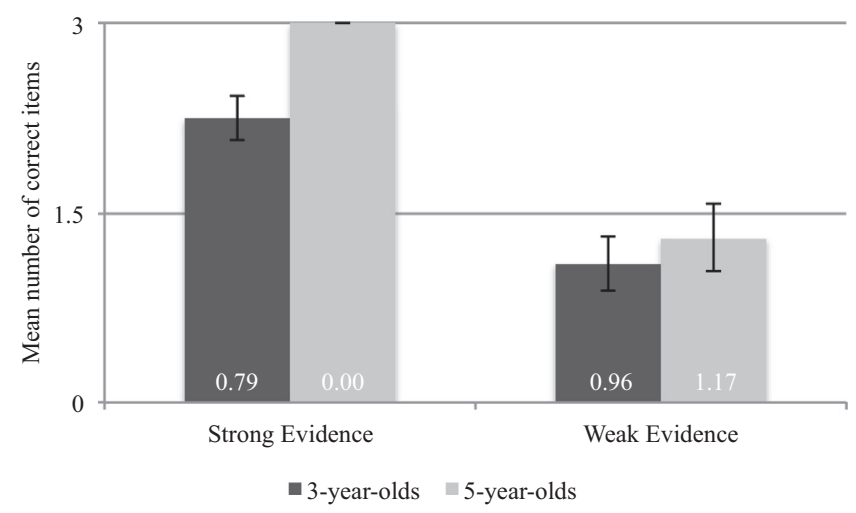

Fig. 4. Mean number of correct items chosen by each age group in weak-evidence and strong-evidence conditions. Error bars indicate standard errors, and numeric values indicate standard deviations.

group (3-year-olds or 5-year-olds) and condition (weak evidence or strong evidence). There was a significant interaction between condition and age group, $F(1,76)=6.15, p=.02, \eta_{\mathrm{p}}^{2}=.06$. The post hoc comparisons suggested that 3-year-olds favored their own items equally in both conditions (Tukey HSD [honestly significant difference], $p=.57$ ), whereas 5-year-olds favored their own items significantly less often in the weak-evidence condition than in the strong-evidence condition (Tukey HSD, $p<.001)$. Moreover, there was no age difference in the way that children favored their own items in the weak-evidence condition (Tukey HSD, $p=.88$ ), but 5-year-olds favored their own items significantly more than 3-year-olds did in the strong-evidence condition (Tukey HSD, $p=.04$ ).

In their justifications, children often used quotes of what they heard without meta-talk such as "Because it is their food" and "In my film, they eat rocks" (3-year-olds: 43\%; 5-year-olds: 68\%). The 3- and 5-year-olds produced meta-talk in their justifications such as "She wasn't sure" and "The selk was sure" only 3\% (4 of 120 questions) and 7\% (8 of 120 questions) of the time, respectively.

\section{Discussion}

The results of Study 2a showed that 3-year-olds mostly chose the items that they had seen in their clips regardless of the reliability of the information they received and regardless of what the puppet partner said, whereas 5-year-olds chose their own items significantly less often when their information source was unreliable than when it was more reliable. However, 5-year-olds' choice of correct items was still at chance in the weak-evidence condition, just like that of 3-year-olds. The age difference between 3- and 5-year-olds was more apparent in the strong-evidence condition than in the weak-evidence condition.

The results of Study 2a clarified the findings with 5-year-olds in Study 1. The results of Study 2a suggest that it is the children who saw the strong-evidence clips who seem to have done more of the interactive work in Study 1. In Study 2, when 5-year-olds saw the strong-evidence clips and the puppet stated that its informant was unsure, 5 -year-olds were confident about their knowledge. Even if their partner disagreed with them (sometimes in Study 1, always in Study 2), they never changed their minds and stuck to their own items. Moreover, when 5-year-olds saw weak-evidence clips, they were more likely to change their minds than when they saw strong-evidence clips. They preferred their own items and the items suggested by the puppet equally frequently. Thus, the combination of these two factors (the confidence by the children who saw strong-evidence clips and the willingness to be convinced by the children who saw weak-evidence clips) seemed to have led 5-year-olds to choose the correct items in Study 1 without much disagreement.

The 3-year-olds' choice of items, on the other hand, was not influenced by the reliability of the information they received or by what the puppet said. In both conditions, 3-year-olds favored their 
own items and changed their minds equally frequently on hearing a conflicting view from the puppet partner. One remaining concern in Study 2a was the high rates of incorrect responses to the control question about certainty: "Was Lisa sure in your film?" In the weak-evidence condition, 3- and 5year-olds answered this question correctly by saying "no" only $30 \%$ and $60 \%$ of the times, respectively. Despite hearing the girl saying, "I am not sure" three times in the weak-evidence clips, and E1 repeating this after each weak-evidence clip, children mostly answered this question by saying "yes." We suspect that this was due to a "yes bias" in children's answers to yes/no questions (Fritzley \& Lee, 2003; Okanda \& Itakura, 2010). Thus, we ran Study 2b, in which we asked additional questions. We first asked two yes/no questions about the certainty of the informant: "Was she sure?" and "Did she say she was sure?" Finally, we asked the forced-choice question "Did she say 'I am sure' or 'I am not sure'?" and gave children two options to choose from to see whether children could accurately report what the informant said. We also simplified the instructions, especially for 3-year-olds, emphasizing that there was a correct item and an incorrect item in each drawer and that the puppet and child would need to find the correct items together.

\section{Study 2b}

\section{Method}

\section{Participants}

In total, 213 -year-olds $(M=3 ; 10$, range $=3 ; 7-4 ; 0,10$ girls $)$ and 195 -year-olds $(M=5 ; 9$, range $=$ $5 ; 6-6 ; 0,10$ girls), who did not participate in Study 1 or Study $2 a$, participated in the current study. The children were native speakers of German and had various socioeconomic backgrounds.

\section{Materials}

The materials were the same as in Study 1 and Study 2a.

\section{Procedure}

The procedure was the same as in Study 2a except for the two following changes:

1. When giving instructions to the child and the puppet, E1 gave simplified instructions and emphasized that there was one correct and one incorrect item in each drawer ("In each drawer, there are two things. But be careful! In each drawer, there is one correct item and there is one incorrect item. If you two find the correct items together, you will both get a surprise gift at the end").

2. When the puppet and the child were deciding on the item, the puppet asked the same set of three questions as she did in Study 2a:

- "What was the [food/drink/sleep] item in your clip?": The 3- and 5-year-olds responded to this question correctly $79 \%$ and $98 \%$ of the time, respectively.

- "Who said that?": The 3- and 5-year-olds responded to this question correctly $57 \%$ and $74 \%$ of the time, respectively.

- "Was she sure?: The 3- and 5-year-olds responded to this question correctly $30 \%$ and $67 \%$ of the time, respectively.

For each item, the puppet asked two more questions about the informant certainty:

- "Did she say she was sure?": The 3- and 5-year-olds responded to this question correctly $35 \%$ and $70 \%$ of the time, respectively.

- "Did she say 'I am sure' or 'I am not sure'?": The 3- and 5-year-olds responded to this question correctly $52 \%$ and $91 \%$ of the time, respectively.

At the end, the puppet asked the child why he or she chose what he or she chose to elicit some justifications. 
Coding

The coding was the same as in Study 2a; we first coded which items children chose and how children justified their choices.

\section{Results}

We analyzed whether children chose the correct items supported by strong evidence and compared the number of correct items chosen by children with chance. The results replicated those of the weak-evidence condition in Study 2a. The 3-year-olds were marginally below chance and mostly chose what they had seen rather than the ones supported by strong evidence, $t(20)=-1.97, p=.06$, $d=0.43$ (see Fig. 5), whereas the 5-year-olds were at chance and did not show a preference between the items they had seen in the videos and the items that the puppet had suggested, $t(18)=-0.96$, $p=.35, d=0.19$ (see Fig. 5). There was also no age difference in children's choice of the correct items, $t(38)=0.32, p=.75, d=0.10$.

Similar to Study 2a, when children were asked to justify their choices, they usually answered the last question by saying things like "Because it is their food" (3-year-olds: 25\%; 5-year-olds: 26\%). Similar to Study 2a, in response to "why" questions, 3-year-olds never used meta-talk in their justifications and 5 -year-olds did so only $10 \%$ of the time.

\section{Discussion}

The results of Study $2 \mathrm{~b}$ replicated the results of Study 2a in terms of children's choice of items and their justifications for these items. Although there was no significant age difference, 3-year-olds preferred their own items more than the items suggested by the puppet, whereas 5-year-olds preferred their items and the items suggested by the puppet equally frequently. More importantly, however, with the addition of the forced-choice control question ("Did she say 'I am sure' or 'I am not sure'?"), the rate of correct answers increased to $52 \%$ for 3-year-olds and $91 \%$ for 5 -year-olds. Thus, the high number of incorrect responses to the certainty question ("Was she sure?") in Study 2 was due to the "yes bias" for 5-year-olds.

The 3-year-olds continued to have difficulty with the certainty question. One explanation for this difficulty could be that, unlike other studies with younger preschool children (e.g., Corriveau \& Harris, 2009; Sabbagh \& Baldwin, 2001) in which children witnessed both informants, children in our study witnessed the testimony of only one informant (without a reference point) and heard the verbal evaluation of the other informant (or a meta-testimony) by the puppet. This required 3-year-olds to comprehend sentences about a third person's mental states or a person's certainty (e.g., "She was not sure"). This difficulty by 3-year-olds is in line with the literature, which shows that children's understanding of others' mental states and their comprehension of third-person references to mental states develop during later preschool ages (Brandt, Buttelmann, Lieven, \& Tomasello, 2016; see also Wellman, Cross, \& Watson, 2001; Wimmer \& Perner, 1983).

\section{General discussion}

Overall, our results showed that when children and their partners received conflicting information from sources that differ in reliability, 5- and 7-year-olds, but not 3-year-olds, trusted the information supported by the strong evidence rather than that supported by the weak evidence in their joint decisions. In Study 1, approximately half of the 7-year-old peers engaged in various kinds of meta-talk in reaching their joint decisions. They verbally evaluated the reliability of the sources (e.g., "She was not sure whether it drinks blue soda," "He said, 'Someone told me ....' What one said may not be correct"). They tried to resolve their disagreement by "publicly" and jointly examining the reliability of the information that each of them had (see Example 1 in "Results" of Study 1). They, in fact, tried to elicit information about the credibility/reliability of the information from one another by asking questions like "How do you know that?" and "Are you sure?" As discussed earlier, talking about the credibility of 


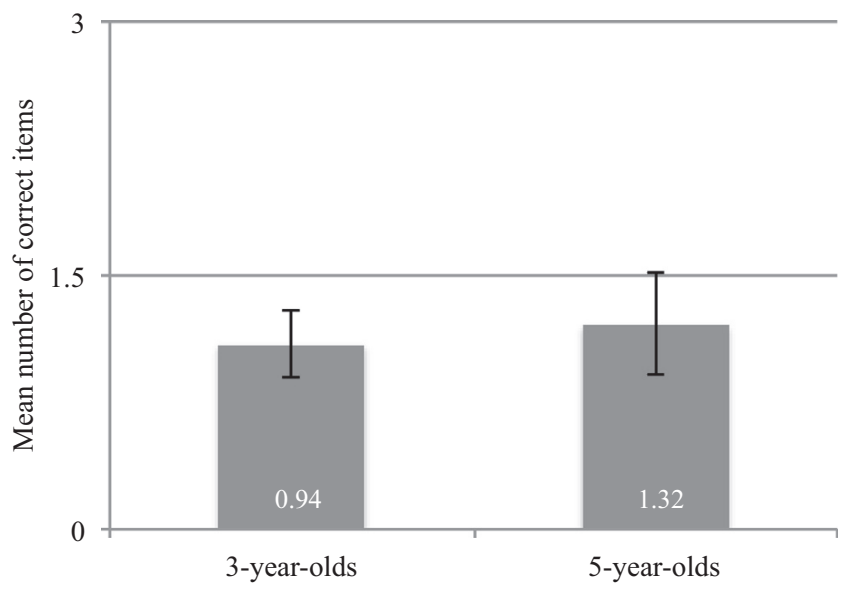

Fig. 5. Mean number of correct items chosen by each age group in weak-evidence condition. Error bars indicate standard errors, and numeric values indicate standard deviations.

information is an advanced meta-cognitive skill that had previously been observed only in adolescents and after intervention (Kuhn et al., 2013). Our findings suggest that as early as 7 years of age, children begin to talk about these to justify their decisions spontaneously in their conversations with peers. The frequency of these meta-argumentative strategies by children potentially increases with age during school ages.

The 5-year-olds, on the other hand, limited their meta-talk to the content of the messages such as "In my story, they ate rocks" and "We did see that in the video" by mentioning the information source without mentioning its reliability. This was true in their spontaneous justifications in Study 1 and elicited justifications in Study 2. However, their choices of items in Study 1 and Study 2 suggest that 5year-olds were sensitive to the reliability of the information source. They were less likely to change their minds, when they received reliable information (from strong-evidence clips) than when they received unreliable information (from the weak-evidence clips). In fact, as the equal reliability condition in Study 1 showed, when both children in a dyad watched weak-evidence clips, they were less likely to express or justify their disagreements than children who watched strong-evidence clips. This suggests that children privately judged that their information source was unreliable, so they did not contradict their peers' choices. Nonetheless, 7-year-olds overall expressed their disagreements more than 5-year-olds did, regardless of whether the information was supported by weak or strong evidence, suggesting that 7-year-olds were more likely to evaluate the information reliability more publicly than 5-year-olds.

The results of Study 1 (together with Examples 1 and 2) and Study 2a suggest that in the unequal reliability condition, children contributed to making correct decisions. The children who saw the strong-evidence clips insisted on their items. The children who saw the weak-evidence clips, on the other hand, were more willing to change their minds. Thus, our findings illustrate that joint decisions made in cooperative peer interactions (or in contexts of trust), in which getting it right benefits both parties, motivates and facilitates young children's reasoning (see also Köymen, Mammen, \& Tomasello, 2016; Köymen, Rosenbaum, \& Tomasello, 2014). In Study 1, two peers, despite their conflicting views on what the correct items were in the unequal reliability condition, had a joint goal of making the right decision, and both age groups were able to reach the correct decisions. More importantly, the two conditions in which the children began with conflicting views seemed to elicit meta-talk in a way that arguing only to win almost certainly would not (because each arguer would then only be seeking to confirm his or her own point of view). Hearing a 
conflicting view in the context of collaborative decision making reminds one not only to question the reliability of one's own knowledge but also to demand that the partner justify his or her line of reasoning and any evidence or reasons for it more fully, perhaps with meta-talk about the overall reasoning process (Kuhn, 2015; Tomasello, 2014).

There is one important question that remains unanswered. In our procedure, the weak-evidence clips involved different markers of unreliability such as limited knowledge access (a second-hand report as opposed to a first-hand report) and expressions of uncertainty (e.g., "I am not sure," "This is strange"). The 5-year-olds referred to the informant's uncertainty only because it was perhaps easier for them to simply repeat what the informant said. However, overall 5-year-olds did not produce enough meta-talk to reach any conclusion. On the other hand, the 7-year-olds referred to knowledge access and uncertainty equally often. This might suggest that 7-year-olds judged both knowledge access and certainty of the informant as important cues to information reliability. Still, we cannot tell from the current data what markers of unreliability mattered more for children. Thus, future research should pit these different markers of unreliability against one another to disentangle what markers of unreliability children pay attention to more.

To conclude, when working toward a joint goal, young children display sophisticated reasoning skills. They are able to disregard their own prior knowledge, especially when they acquired this knowledge from an unreliable source, and accept the alternative proposed by their peer. They also begin to use meta-talk in their spontaneous peer conversations to justify their proposals. Our results support the view that children's joint reasoning is a fundamentally cooperative enterprise aimed at making jointly rational decisions.

\section{Acknowledgments}

We thank Katharina Haberl, Isabelle de Gaillande-Mustoe, Ramona Frickel, Martina Deitrich, and Julia Ohl for their help in recruiting children and collecting data; Pia Fischer, Joanna Buryn-Weitzel, Silvan Holverstein, Alice Dabbagh, and Felix Engelmann for their help in coding; Philipp Brandstädter for the drawings; Susanne Mauritz for her help with the recordings and Wencke Assmann for voicing the clips; Ronny Barr for his help in editing the clips; and all of the day-care centers and children for their friendly cooperation.

\section{Appendix A. The strong evidence clips}

Set 1


Appendix A (continued)

Set 1
Wir trinken blaue/grüne Limonade. Schau wie ich hier
blaue/grüne Limonade trinke. Wir trinken nur blaue/
grüne Limonade, nichts anderes.
'We drink blue/green soda. Look how I drink
blue/green soda here. We drink only blue/green
soda, nothing else.'

Appendix B. The weak-evidence clips.

Hallo ich bin Lisa. Ich habe von einem interessanten Tier gehört. Ich
glaube, sie heißen Selks.
'Hello I am Lisa. I heard about an interesting animal. I believe they
are called selks.'




\section{References}

Brandt, S., Buttelmann, D., Lieven, E., \& Tomasello, M. (2016). Children's understanding of first and third person perspectives in complement clauses and false belief tasks. Journal of Experimental Child Psychology, 151, 131-143.

Corriveau, K. H., \& Harris, P. L. (2009). Preschoolers continue to trust a more accurate informant 1 week after exposure to accuracy information. Developmental Science, 12, 188-193.

Corriveau, K. H., \& Kurkul, K. E. (2014). "Why does rain fall?": Children prefer to learn from an informant who uses noncircular explanations. Child Development, 85, 1827-1835.

Dunn, J., \& Munn, P. (1987). Development of justification in disputes with mother and sibling. Developmental Psychology, 23, 791-798.

Fritzley, V. H., \& Lee, K. (2003). Do young children always say yes to yes-no questions? A metadevelopmental study of the affirmation bias. Child Development, 74, 1297-1313.

Koenig, M. A., \& Harris, P. L. (2005). Preschoolers mistrust ignorant and inaccurate speakers. Child Development, 76, 1261-1277.

Köymen, B., Mammen, M., \& Tomasello, M. (2016). Preschoolers use common ground in their justificatory reasoning with peers. Developmental Psychology, 52, 423-429.

Köymen, B., Rosenbaum, L., \& Tomasello, M. (2014). Reasoning during joint decision-making by preschool peers. Cognitive Development, 32, 74-85.

Kuhn, D. (2001). How do people know? Psychological Science, 12, 1-8.

Kuhn, D. (2015). Thinking together and alone. Educational Researcher, 44, 46-53.

Kuhn, D., Zillmer, N., Crowell, A., \& Zavala, J. (2013). Developing norms of argumentation: Metacognitive, epistemological, and social dimensions of developing argumentive competence. Cognition and Instruction, 31, 456-496.

Kyratzis, A., \& Ervin-Tripp, S. M. (1999). The development of discourse markers in peer interaction. Journal of Pragmatics, 31 , $1321-1338$.

Legare, C. H. (2012). Exploring explanation: Explaining inconsistent evidence informs exploratory, hypothesis-testing behavior in young children. Child Development, 83, 173-185.

Mahr, J., \& Csibra, G. (2017). Why do we remember? The communicative function of episodic memory. Behavioral and Brain Sciences. https://doi.org/10.1017/S0140525X17000012. Advance online publication.

Mercier, H., Bernard, S., \& Clément, F. (2014). Early sensitivity to arguments: How preschoolers weight circular arguments. Journal of Experimental Child Psychology, 125, 102-109.

Mercier, H., \& Sperber, D. (2011). Why do humans reason? Arguments for an argumentative theory. Behavioral and Brain Sciences, 34, 57-74.

Okanda, M., \& Itakura, S. (2010). When do children exhibit a "yes" bias? Child Development, 81, 568-580.

Sabbagh, M. A., \& Baldwin, D. A. (2001). Learning words from knowledgeable versus ignorant speakers: Links between preschoolers' theory of mind and semantic development. Child Development, 72, 1054-1070.

Sobel, D. M., \& Corriveau, K. H. (2010). Children monitor individuals' expertise for word learning. Child Development, 81, 669-679.

Sperber, D., Clément, F., Heintz, C., Mascaro, O., Mercier, H., Origgi, G., \& Wilson, D. (2010). Epistemic vigilance. Mind and Language, 25, 359-393.

Tomasello, M. (2014). A natural history of human thinking. Cambridge, MA: Harvard University Press.

Wellman, H. M., Cross, D., \& Watson, J. (2001). Meta-analysis of theory-of-mind development: The truth about false belief. Child Development, 72, 655-684.

Wimmer, H., \& Perner, J. (1983). Beliefs about beliefs: Representation and constraining function of wrong beliefs in young children's understanding of deception. Cognition, 13, 103-128.

Young, A. G., Alibali, M. W., \& Kalish, C. W. (2012). Disagreement and causal learning: Others' hypotheses affect children's evaluations of evidence. Developmental Psychology, 48, 1242-1253. 